\title{
Egyptian pediatric clinical practice guidelines for urinary tract infections in infants and children (evidence based)
}

\author{
Bahia H. Moustafa I* (D), Moftah M. Rabie ${ }^{2}$, Ihab Z. El Hakim³ ${ }^{3}$ Ahmed Badr ${ }^{1,4}$, Moustafa El Balshy ${ }^{5}$, \\ Nesreen Mohamad Kamal ${ }^{6}$, Ragia Marei $\mathrm{Ali}^{3}$ and Pediatric Nephrology Work Group
}

\begin{abstract}
Background: National evidence-based recommendations for diagnosis, treatment, imaging, and follow-up in urinary tract infection are crucial being a major health problem in pediatrics. Every region should follow international recommendations with respect to the disease local profile and available facilities for that area.

Methods: Based on AGREE II (the assessment tool of practice guidelines), Egyptian CGLs used *American Academy Pediatrics, ${ }^{*}$ European Association Urology, European Society Pediatric Urology, and *Asian Association Urinary tract infections as its evidence-based references. Health questions were listed for evidence base answers adopted from selected CGLs after their permission. Key statements were approved by all members and further approved by the Egyptian Pediatric Guidelines Committee after local and international external peer reviewing.

Results: (1) Diagnosis recommendations: Urine culture with diagnostic colony counts is essential for diagnosis. Catheter samples are important for critical cases and non-toilet-trained cases especially when they show significant bacteriuria and pyuria. (2) Treatment plan included areas of debate as choice of antibiotic, oral versus intravenous, duration, antibiotic prophylaxis considering age, disease severity, recurrence, + risk factors, and imaging reports. (3) Imaging recommendations were tailored to suit our community. Renal bladder ultrasound is important for children with febrile UTI, due to the high prevalence of congenital anomalies of the kidney and urinary tract, paucity of prenatal ultrasound, and lack of medical documentation to reflect previously diagnosed UTI or US reports. We recommend renal isotopic scan and voiding cystography for serious presentation, high-risk factors, recurrence, and abnormal US. (4) Urological consultation is recommended: in urosepsis or obstruction, male infants $<6$ months. Acute basal DMSA is recommended in congenital renal hypodysplasia. Six months post-infection, US and DMSA are recommended in severe pyelonephritis and vesico-ureteric reflux, where those with abnormal US or DMSA or both should have voiding cystography. (5) Follow-up recommendations include family orientation with hazards of noncompliance and monitoring at pregnancy.
\end{abstract}

\footnotetext{
*Correspondence: moustafa_afpna@hotmail.com

${ }^{1}$ Department of Pediatrics, Pediatric Nephrology \& Transplantation Unit, Kasr Al Ainy Faculty of Medicine, Cairo University, 35 Elsheikh Aly Youssef Kasr Alainy, Cairo 11441, Egypt

Full list of author information is available at the end of the article Intellectual property rights are reserved to members of the Egyptian Pediatric Clinical Practice Guidelines Committee (EPCGC) - Ashraf Abdel Baky (Head of Committee)/Pediatric Nephrology Work Group (Bahia Moustafa principal author).
}

(c) The Author(s) 2021. Open Access This article is licensed under a Creative Commons Attribution 4.0 International License, which permits use, sharing, adaptation, distribution and reproduction in any medium or format, as long as you give appropriate credit to the original author(s) and the source, provide a link to the Creative Commons licence, and indicate if changes were made. The images or other third party material in this article are included in the article's Creative Commons licence, unless indicated otherwise in a credit line to the material. If material is not included in the article's Creative Commons licence and your intended use is not permitted by statutory regulation or exceeds the permitted use, you will need to obtain permission directly from the copyright holder. To view a copy of this licence, visit http://creativecommons.org/licenses/by/4.0/. 
Conclusion: Diagnosis and treatment show strong recommendations. Imaging depends on patient assessment. Referral to a pediatric nephrologist and urologist in complicated cases is crucial. Follow-up after the age of 16 years in adult clinics is important.

Keywords: Evidence based, Guidelines, Urinary tract infections, Infants and children

\section{Background}

Most clinical guidelines for urinary tract infections (UTIs) come from Western countries, some from Asia, and almost none from Africa. The aim of these clinical guidelines is to have key statements that respect evidencebased international recommendations tailored to suit the community. These guidelines address the evaluation, diagnosis, and treatment of UTI in infancy and childhood. While the recommendations are suitable for the Egyptian community, international stakeholders can modify specific contents as needed, when system-level barriers hamper adoption of the best practice recommendations. The prevalence of symptomatic and asymptomatic bacteriuria in Egypt ranges between 22 and 14.6 and 11.4\% [1-3]. The chief organisms were reported to be Escherichia coli, Klebsiella, Proteus, and Pseudomonas [4]. Vesico-ureteric reflux (VUR) is reported in $18-22 \%$ and renal scarring in 8-33\% [4]. Congenital anomalies of the kidney and urinary tract (CAKUT) account for 44-33\% of children with end-stage renal disease (2015/2017; Egyptian registry for ESRD) compared to 7\% in the US 2005 registry [5]. Grading of risk factors associated with UTI has been reviewed by the Italian Society of Pediatric Nephrology (PN) [6]. The diagnosis of UTI depends on clinical features confirmed with significant bacteriuria. The plan of radiologic imaging should consider the safety, sensitivity, and limitations of different modalities. Therapy depends on the severity of the clinical features.

\section{Methods}

A Pediatric Nephrology Work Group (PNWG) was constituted with members from all universities. None of the participants had competing interests or potential conflicts. During 2017-2018, the work group reviewed the pediatric literature specifically guidelines to select those suitable to our community. Updates were based on evidences generated over the past decades and adapted from the Asian Association Urinary tract infection/ Sexually transmitted diseases (AAUS), European Society Pediatric Urology (ESPU), European Association Urology (EAU), and American Academy Pediatrics (AAP) to cover diagnosis, treatment, imaging, and follow-up. Based on AGREE II [7], guidelines from AAP, AAUS, and EAU/ESPU were selected as references for adoption or adaption [8-10]. AGREE II (2017) is the new international tool for the evaluation and assessment of practice guidelines (Table 1). It is valid and reliable, comprises 23 items organized into 6 quality domains for scoring with the final overall rating report [7]. Clinical questions (Table 2) were put in PIPOH format (Patient population, Intervention, Professionals, Outcomes, Healthcare settings/content) (Table 3) [11, 12], searching for evidencebased answers. Evidences were reviewed by a clinical epidemiologist to revise its reference and quality (which guideline? evidence level rating? adopted or adapted?). Recommendations were formulated and peer reviewed followed by a re-review by the working group [11]. The guidelines were adopted in 2018, with a proposed update in 2021.

\section{Evidence levels and recommendation grades}

Evidence-based practice uses the best current evidence in making decision about the care of the patient when grading recommendations. Levels of evidences called hierarchy of evidence are assigned to studies based on the methodological quality of their designs, validity,

Table 1 Agree II

\begin{tabular}{|c|c|c|c|c|c|c|c|c|}
\hline AAP 2012 & Total & Final score & Asian 2015 & Total & Final score & European 2014 & Total & Final score \\
\hline Domain 1 & 139 & $79.90 \%$ & Domain 1 & 97 & 91.11111111 & Domain 1 & 32 & 72.22222222 \\
\hline Domain 2 & 121 & $67.40 \%$ & Domain 2 & 93 & 86.66666667 & Domain 2 & 30 & 66.66666667 \\
\hline Domain 3 & 341 & $72 \%$ & Domain 3 & 242 & 84.16666667 & Domain 3 & 81 & 67.70833333 \\
\hline Domain 4 & 127 & $71.50 \%$ & Domain 4 & 94 & 87.77777778 & Domain 4 & 31 & 69.44444444 \\
\hline Domain 5 & 161 & $67.20 \%$ & Domain 5 & 110 & 75 & Domain 5 & 36 & 58.33333333 \\
\hline Domain 6 & 84 & $70.80 \%$ & Domain 6 & 62 & 86.66666667 & Domain 6 & 21 & 70.83333333 \\
\hline Total domain & 973 & $71.50 \%$ & Total domain & 698 & 84.49275362 & Total domain & 231 & 67.02898551 \\
\hline Overall agreement & 46 & $79.20 \%$ & Overall agreement & 29 & 80 & Overall agreement & 10 & 66.66666667 \\
\hline
\end{tabular}


Table 2 Health questions

\begin{tabular}{|c|c|}
\hline \multicolumn{2}{|c|}{ Health questions used to develop this adapted CPGL } \\
\hline \multicolumn{2}{|c|}{$\begin{array}{l}\text { These questions concern children } 1 \text { month to } 16 \text { years with UTI, attending the primary health care service units treated by general pediatricians or } \\
\text { general physicians and those managed in specialized Pediatric Nephrology units. They aim to identify those with risk factors, recurrent or complicated } \\
\text { presentations, improve child's symptoms, prevent complications, and shorten the duration of hospital admission. }\end{array}$} \\
\hline 1 & What are the risk factors of UTI that should be searched for? \\
\hline$\underline{2}$ & When the suspicion of UTI would be aroused? \\
\hline$\underline{3}$ & When to ask for urine analysis? What tests to ask for? \\
\hline$\underline{4}$ & $\begin{array}{l}\text { When would the physicians ask for a urine culture? What is the best tech- } \\
\text { nique to get the urine sample for culture? }\end{array}$ \\
\hline$\underline{5}$ & $\begin{array}{l}\text { When to start empirical antibiotics and which to be used? Oral or paren- } \\
\text { teral? Duration? }\end{array}$ \\
\hline$\underline{6}$ & What is the duration of antibiotic therapy proved by culture? \\
\hline$\underline{7}$ & When the suspicion of resistance to the therapy would be aroused? \\
\hline$\underline{8}$ & When to recommend prophylactic antibiotic? \\
\hline$\underline{9}$ & $\begin{array}{l}\text { When further blood investigations would be requested, such as kidney } \\
\text { function, acute phase reactants and complete blood count? }\end{array}$ \\
\hline$\underline{10}$ & $\begin{array}{l}\text { When would the general practitioner refer patients to specialized PN care } \\
\text { services and pediatric nephrology units? }\end{array}$ \\
\hline$\underline{11}$ & When to refer to the urologist? \\
\hline$\underline{12}$ & $\begin{array}{l}\text { When would the physicians request abdominal ultrasound? When and } \\
\text { what further imaging might be needed? }\end{array}$ \\
\hline$\underline{13}$ & Follow-up recommendations and suggested documentation. \\
\hline
\end{tabular}

and applicability to patient care, thus given the grade or strength of recommendation (Fig. 1). The highest levels are designed to be unbiased with less risk of errors and fit to guide practice decisions. Strong evidence includes clinical practice guidelines using systematic reviews with meta-analysis, systematic reviews alone, randomized controlled trials, and non-randomized control studies. The weakest level of evidence includes authorities' opinion or expert committee report. The following Table 4 represents an example for evidence level and recommendation grading as an example used by the Spanish Argon Institute of Sciences.

\section{Results}

Key statements (diagnosis, treatment, imaging, follow-up) Diagnosis recommendations

The diagnosis of UTI The diagnosis of UTI is difficult in neonates and infancy where fever without a focus may be the chief presentation. Clinical features alone may not be sufficient to diagnose UTI. Confirmatory laboratory tests are required (LE1a, GR: A; EAU/ESPU) (LE: 1, GR: A; AAUS).

Clinical features of lower UTI as well as upper in relation to age are shown in Table 5 [13].
Features suggestive of UTI or predicting kidney damage (risk factors) include recurrent fever of unknown focus, previously suggested or confirmed UTI, poor urine flow or abnormal voiding pattern, constipation or bladder bowel dysfunction BBD, abnormal fetal ultrasonography, family history of renal disease, abnormal back and spine, abnormal external genitalia, e.g. phimosis or fused labia (EL2) (AAP), females (EL3) (AAP), uncircumcised boys (EL3) (AAP), formula feeding (EL2), and hygiene $[6,13-17]$.

When to ask for urine tests? Infants and children with features suggestive of UTI, fever $\left(\geq 38^{\circ} \mathrm{C}\right)$ without localization or with an alternative site of infection who remain unwell and refractory to treatment (EL3) (AAP 2011, AAP 2019) $[10,18]$.

What urine tests are needed? Urine analysis (dipsticks for nitrites and leukocyte esterase and microscopy for pus cells and bacteria). Urine culture should be done in all cases.

When to ask for a urine culture? Age $<3$ years, recurrent UTI, positive result for either nitrites or leukocyte esterase or both, clinical symptoms do not fit with dipstick, suspecting pyelonephritis APN, no response to antibiotic treatment after $48 \mathrm{~h}$, and those who are seriously ill [19]. 
Table 3 PIPOH model

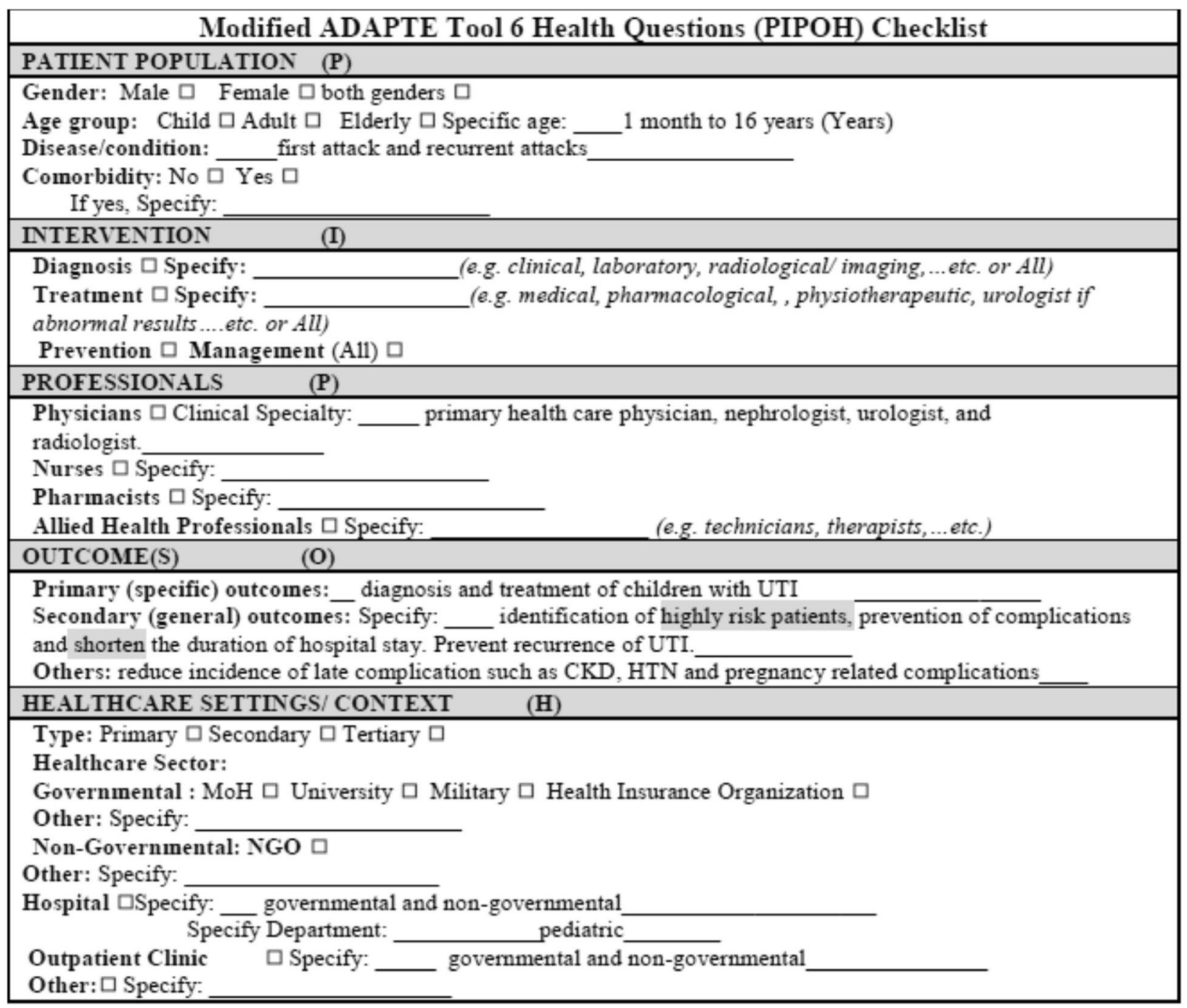

How to collect the urine sample? Pre-toilet-trained children who are seriously ill, with or without suspected UTI, require urgent antibiotic therapy. We recommend urine to be collected by either bladder catheter or suprapubic aspirate (SPA) (EL3, GR: A; AAUS); since SPA is a painful procedure, we prefer catheterization. When UTI is less suggested and the clinical features are not serious to indicate immediate therapy with antibiotics, urine may be collected by a urine bag; positive or equivocal results are confirmed with a catheter sample. The Quick Wee voiding stimulation method is also suggested as an option [18-20]. For toilet-trained children, a clean-catch midstream morning sample is recommended (Fig. 2).

How to interpret results of the urine analysis? The nitrite test is not a sensitive marker because
Pseudomonas and most gram-positive bacteria do not produce nitrites. The test may also be negative with frequent voiding. Overall, the test has a sensitivity of $79 \%$ and a specificity of $87 \%$. Results of leukocyte esterase are not reliable. The test has a sensitivity of $50 \%$ and a specificity of $98 \%$. Dipstick test, with positive either LE or nitrites (sensitivity $88 \%$, specificity $79 \%$ ) or both (sensitivity $45 \%$, specificity $98 \%$ ), is helpful for the diagnosis [13]. Leukocyturia and bacteriuria: Patients with febrile UTI show leukocytes in urine with a low count. Low count bacteriuria with multiple pathogens and no leukocyturia suggest contamination. Bacteriuria without pyuria in asymptomatic patients is interpreted as asymptomatic bacteriuria [18, 21]. Urine samples should be refrigerated to avoid the overgrowth of organisms. Urine culture is the gold standard to diagnose UTI. The cutoff 


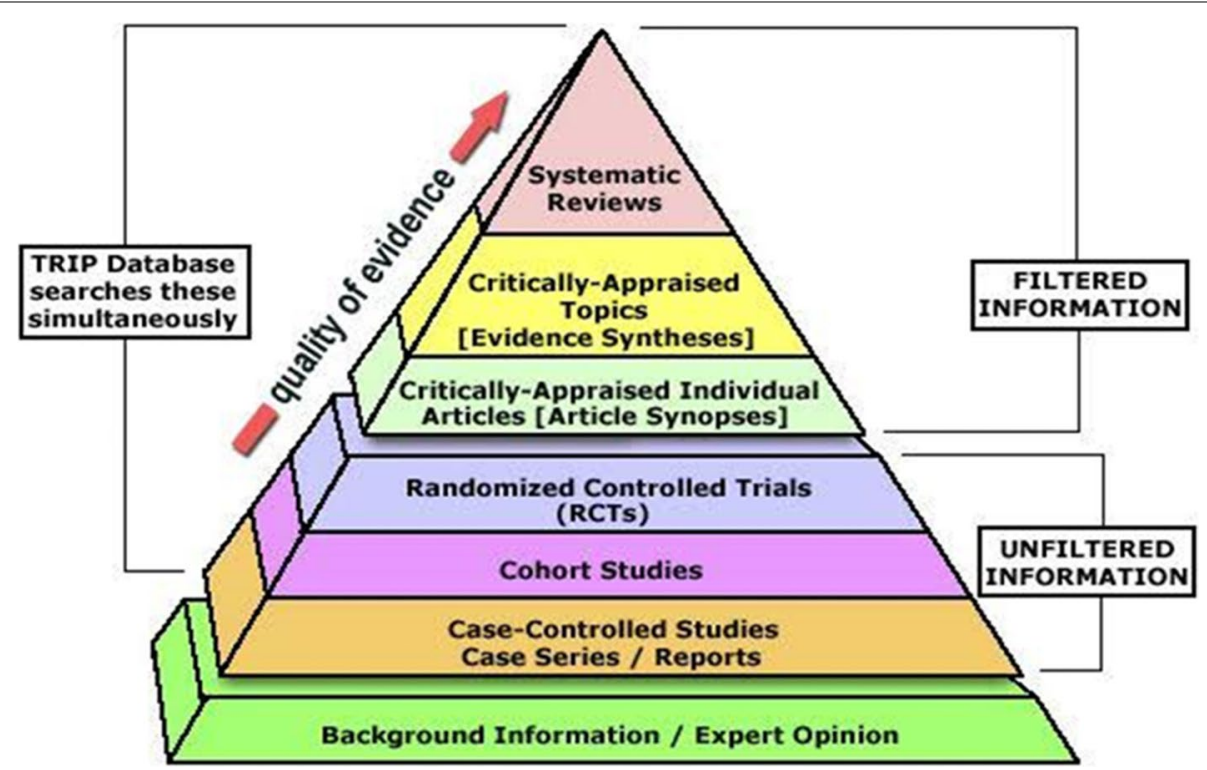

Fig. 1 Levels of evidences (hierarchy of evidence level). https://images.app.goo.gl/Zd2XL933/i/wFJNA9

Table 4 Level of evidence and grades of recommendation based on study design

\begin{tabular}{|c|c|}
\hline Level o & \\
\hline LE: I a & *Systematic review \\
\hline LE: I b & *Level 1 studies masked comparison with a valid reference test, adequate spectrum of pt. \\
\hline LE: II & $\begin{array}{l}\text { Level } 11 \text { studies (have one of these } \\
\text { *unrepresentative sample } \\
\text { *inadequate comparison with the reference standard } \\
\text { *unmasked comparison, case-control studies) } \\
\text { *Systematic review of level } 11 \text { studies }\end{array}$ \\
\hline LE: III & *Level III studies (have 2 or more described in level II studies) [12] \\
\hline Grades & \\
\hline GR: A & $\begin{array}{l}\text { *At least one meta-analysis, systematic review, or clinical trial rated } 1++ \text {, body of evidence of studies rated } \\
1+\text { with the overall consistency of results }\end{array}$ \\
\hline GR: B & $\begin{array}{l}\text { *Body of evidence of studies rated } 2++ \text { applicable to the target, with the overall consistency of results or } \\
\text { *Evidence extrapolated from studies rated } 1++ \text { and } 1+\end{array}$ \\
\hline GR: C & $\begin{array}{l}\text { *Body of evidence of studies rated } 2+\text { applicable to the target, with the overall consistency of results } \\
\text { *Evidence extrapolated from studies rated } 2++\end{array}$ \\
\hline GR: D & $\begin{array}{l}\text { *Evidence level } 3 \text { or } 4 \text { or extrapolated from studied 2+ } \\
{ }^{*} \text { CGLs for UTI in children Argon Institute of Health Sciences (1+CS), 2011, SNS CGLs (1+CS) No 2009/01 [12]. }\end{array}$ \\
\hline
\end{tabular}

Rating evidence level in Egyptian National CGLs was related to its reference guideline as adopted after their permission. AAP used L1, L2, and L3. AAUS used L1, L2, and $L 3$ and GR: $A, B, C$, and D. EAU/ESPU used L1a, L1 b, and L2 and GR: A, B, C, and D

Table 5 Clinical features in relation to age

\begin{tabular}{ll}
\hline Age group & Symptoms and signs \\
\hline $\begin{array}{l}\text { Infants and prever- } \\
\text { bal children }\end{array}$ & $\begin{array}{l}\text { Fever, vomiting, lethargy, irritability, poor feeding, } \\
\text { failure to thrive, abdominal pain, jaundice, hema- } \\
\text { turia, offensive urine, crying on passing urine }\end{array}$ \\
Verbal children & $\begin{array}{l}\text { Dysuria, frequency, urgency, new-onset incon- } \\
\text { tinence, abdominal or flank pain, suprapubic } \\
\text { discomfort, vomiting, fever, hematuria, cloudy or } \\
\text { offensive urine }\end{array}$ \\
\hline
\end{tabular}

level of bacterial count to diagnose infection depends on the method of urine collection. Urine culture is considered positive if the catheter sample has $\geq 50,000 \mathrm{CFU} /$ $\mathrm{ml}$ of micropathogen (EL 3) or clean-catch sample $\geq 100,000$ CFU (EL3) [18]. Other tests as blood leukocyte count, C-reactive protein, and erythrocyte sedimentation rate are not helpful to diagnose upper UTI. Procalcitonin is a satisfactory marker for renal parenchymal affection (LE3, GR: B; AAUS) [22]. 


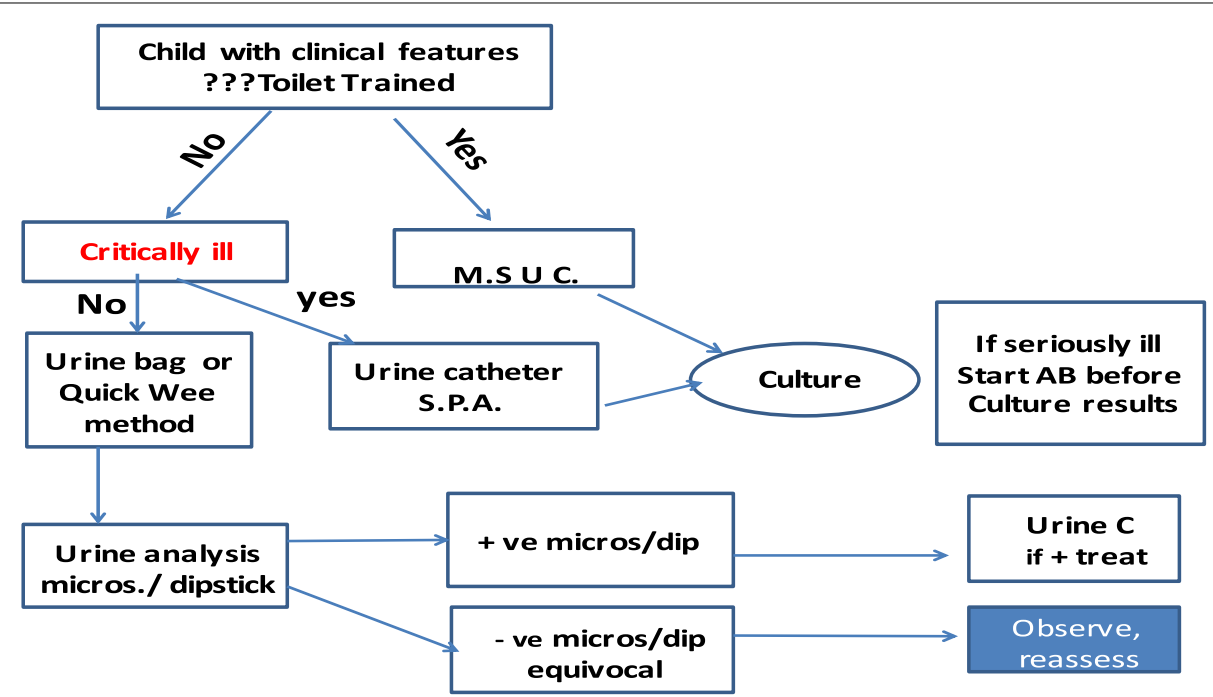

Fig. 2 National diagnostic workup plan. M.S.U.C midstream urine collection, S.P.A.S suprapubic aspirate sample, Cath catheterization, + ve positive, - ve negative, micros. microscopy, L. E leukocyte esterase, N nitrite, +ve dip/micros. both are positive, -ve dip/micros both are negative, equivocal positive dip, negative microscopy, or vise versa, Urine C \& S urine culture and sensitivity, AB antibiotic

The diagnostic workup is summarized in Fig. 2.

\section{Treatment recommendations}

When to start antibiotic therapy $(A B)$ ? We recommend to start empiric $A B$ immediately after a urine sample is taken for culture in those with serious condition, recurrent presentation, with risk factors, or showing high clinical suspicion index of UTI (L2GR:A.AAUS). The reason behind that is to improve the clinical condition and prevent bacteremia and renal damage (L2GR:B. AAUS) [6, 22].

Which antibiotic to use? The choice of empiric $\mathrm{AB}$ depends on patient age, severity of clinical presentation, localization of UTI, expected pathogen, and resistance pattern in the community (L2GR: A, AAUS). Final AB to be adjusted after cultural results (L2GR: B; AAUS) [8, 22]. Common empiric parenteral $\mathrm{AB}$ are ceftriaxone, cefotaxime, ceftazidime, gentamycin, and tobramycin. Common empiric oral $\mathrm{AB}$ are amoxicillin clavulanate, trimethiprim sulfamethoxazole, cefixime, and cefpodoxime [9].

Which route? Initial therapy with oral or parenteral is equally efficacious for children $>3$ months with uncomplicated UTI. IV is indicated in young age, septicemia, vomiting or diarrhea, noncompliance, and complicated UTI (L2GRA, AAUS) [8, 22]. Treatment plan: For infants and children with cystitis, we recommend oral $\mathrm{AB}$ for 3-5 days, e.g. cephalosporins $50-100 \mathrm{mg} / \mathrm{kg}$ or TMP $5-6 \mathrm{mg} / \mathrm{kg}$, or TMP $/$ sulfamethoxazole $56 \mathrm{mg} / \mathrm{kg}$, or amoxicillin/clavulanic $37.5-75 \mathrm{mg} / \mathrm{kg}$, or nitrofurantoin $3-5 \mathrm{mg} / \mathrm{kg}$. If the patient remains unwell, reassess and send urine for culture/sensitivity, in case another diagnosis has not been made. For patients with uncomplicated pyelonephritis, who are older than 6 months of age and who show normal US, we recommend to start oral empiric $A B$ as cephalosporin and readjust after culture results (for 7-10 days total duration). If remains unwell, re-culture and refer to pediatric nephrologists. For complicated pyelonephritis, for all ages, we recommend parenteral ceftazidime and ampicillin or aminoglycoside and ampicillin for 7 days to be shifted to oral route when clinical condition allows (L1, B) (EAU/ESPU 2014) [9]. No sufficient data is available to compare 7 -versus 14-day treatment course for APN. If gentamicin is prescribed, a single daily dose is recommended with monitoring renal function (L2) (AAP) $[18,23]$.

When to hospitalize? Infants and children of any age with serious presentation or infants $<3$ months with suspected UT or infants and children with a previous diagnosis of complicated or recurrent UTI (reflux, malformation, obstruction, renal scars) or those with atypical presentation as associated hypertension, proteinuria, anemia, and impaired renal functions should be hospitalized with immediate sepsis screen and urine culture and parenteral antibiotic (L1, B) EAU/ESPU [9], 
(L2, GR: C; AAUS) [22]. Resistance to AB occurs with urologic anomalies, obstruction, resistant pathogen and in infants $<3$ months. Clinical examination of these cases shows fever, flank tenderness, and mass with leukocytosis, azotemia, and US report obstruction (L2GRB AAUS) [24-26].

When to recommend $A B$ prophylaxis? The potential benefit of preventing recurrent UTI with $A B$ prophylaxis should be weighed against the risk of $A B$ resistance in future infections (L2GR: B AAUS) [22]. Therefore, it is considered in recurrent UTI with and without VUR. It is also indicated to prevent infection in grade (III-V) VUR (L1 b, GR: B) [23, 27]. Asymptomatic bacteriuria (no symptoms, significant bacteriuria, no pyuria) should not be treated with antibiotics (LE2, GR: B) EAU/ESPU, AAP $[9,18,27]$.

When to refer to pediatric nephrologists? Infants < 3 months age, serious presentation at any age, presence of RF, recurrent course, abnormal US, resistance to $A B$ therapy, associated proteinuria, hypertension anemia, impaired kidney functions (consensus).

When should you ask for urologic consultation? Seriously ill suspecting urosepsis (LE1a, GR:A) (EAU/ ESPU), obstruction (patient is oliguric with bladder or renal mass) (LE1b, GR:A) (EAU/ESPU), resistance to AB recommended by culture (LE2a, GR:B), abnormal US suggesting obstruction, VUR, malformation (LE2a, GR:B EAU/ESPU) [9], voiding disorder, abnormal genitalia, sacral agenesis (L2, GR:B, AAUS) [22] for interference (nephrostomy, stent, diversion), and imaging plan (LE2a, GR:B) (EAU/ESPU) [9] (Fig. 6).

\section{Imaging recommendations}

Imaging studies are not routine investigations in every case with UTI. It is recommended by most clinical guidelines in recurrent, serious, resistant, positive high-risk factors (HRF) as $<6$ months age boy, positive family history, and non-E. coli. They are either basal or follow-up $[6,18]$. The aim of imaging is to localize the site of infection, look for anomalies or obstruction, VUR, and congenital or acquired renal scars (LE: 2, GR: B) (AAUS) [6, $10,18,22]$.

When and why to ultrasound? RBUS is the first recommended imaging tool. Most CGLs recommend US in UTI; when serious presentation, or high-risk patients, or recurrent UTI, or antibiotic resistant, or suspected obstruction $[6,9,10]$. AAUS recommends its routine use for any child with febrile UTI as soon as possible (L3, GR: C) (AAUS 2015) [22] and EAU/ESPU 2014 supports this if unavailable prenatal or pre-existing ultrasound (L2aGR: B) (EAU/ESPU) [9]. Tsai added to be followed 6 months later in children with severe acute pyelonephritis (APN) and those with vesico-ureteric reflux (VUR) (LE3, GR:

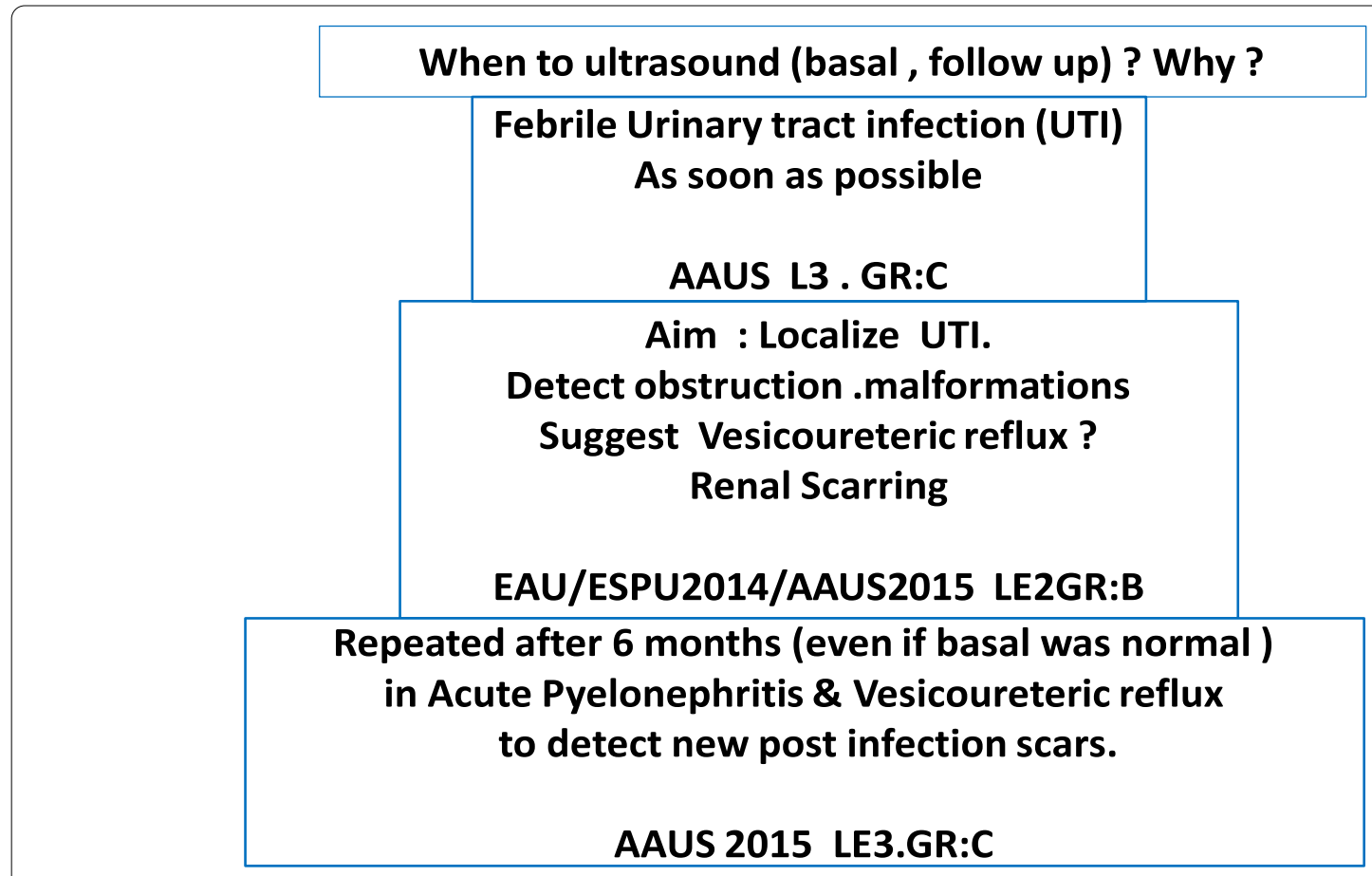

Fig. 3 National guideline. When and why to ultrasound? 
C) (AAUS) (Figs. 3 and 4) [22]. The NICE group did not recommend it in the simple responsive first episode of febrile UTI if older than 6 months waiting for recurrence, and considered US essential only for complicated and recurrent cases of any age. The NICE group also avoided its use in the acute phase (except in atypical complicated cases) to avoid false-positive data [18, 28].

National CGLs recommend:

- Basal US imaging in UTI for any patient with febrile UTI and not only those with recurrent, resistant course or RF, once culture results are confirmative and not to wait for 6 weeks after (LE3, GR: C) (AAUS 2015) $[9,22,28]$. Our reasons rely on the high prevalence of congenital anomalies of the kidney and urinary tract (CAKUT) in our community (34-44\% of ESRD), paucity of the antenatal US or patient documentation for previous UTI episodes or US reports, and family noncompliance for follow-up. US affords screening for malformations as well. Of note, in a cohort study of 107 Egyptian CAKUT patients (age range 2 weeks to 13 years), UTI was a predominant manifestation in $76 \%$ of patients, both obstructive and non-obstructive CAKUT patients, hence the paramount importance of imaging in pediatric UTI [29]. It is better to be as soon as possible to avoid family noncompliance with dropout for postponed imaging.

- We also recommend that whenever basal US suggests obstruction, congenital renal scarring, VUR, and also when the patient is a male infant $<6$ months, infants of either sex, or with a serious presentation at any age or with abnormal genitalia, urological consultation must be done. These patients may need urgent interference (ureteric diversion, stents) or further imaging as mercaptoacetyltriglycine diuretic renogram (MAG3), voiding cystourethrography (VCUG), dimercaptosuccinic acid scan, and acute DMSA (ADMSA) [9, 28] (Fig. 6).

- These CGLs also recommend, for those with acute pyelonephritis (APN), or those with VUR, to repeat ultrasound (follow-up US) 6months after an acute episode of UTI to report for new scars (LE2, GR:C) (AAUS) $[9,22]$ (Figs. 3 and 4). European CGLs confirmed the US role in all forms of UTI for making further imaging plans as DMSA and VCUG as being more sensitive in the diagnosis of VUR or renal scars (LE2a EAU/ESPU) [9]. US follow-up in recurrent cases is essential to follow renal growth as well [4] (Figs. 3 and 4).

When and how to extend imaging behind US (Reno gram/ VCUG) (Figs. 3, 4, and 5) Because of the limited sensitivity of US in the diagnosis of VUR and renal scarring, Egyptian CGLs 2018, AAUS 2015, and EAU 2014 recommended to extend imaging behind US to DMSA and VCUG for severe acute pyelonephritis, vesico-ureteric reflux, abnormal basal or 6months post-infection followup US, recurrent UTI, and presence of risk factors (RFs) (L3GR:C, L2GR:B AAUS15) [22] (Figs. 4 and 5). NICE 16 recommends to extend the imaging plan behind RBUS only for atypical, recurrent, young age below 3 years,

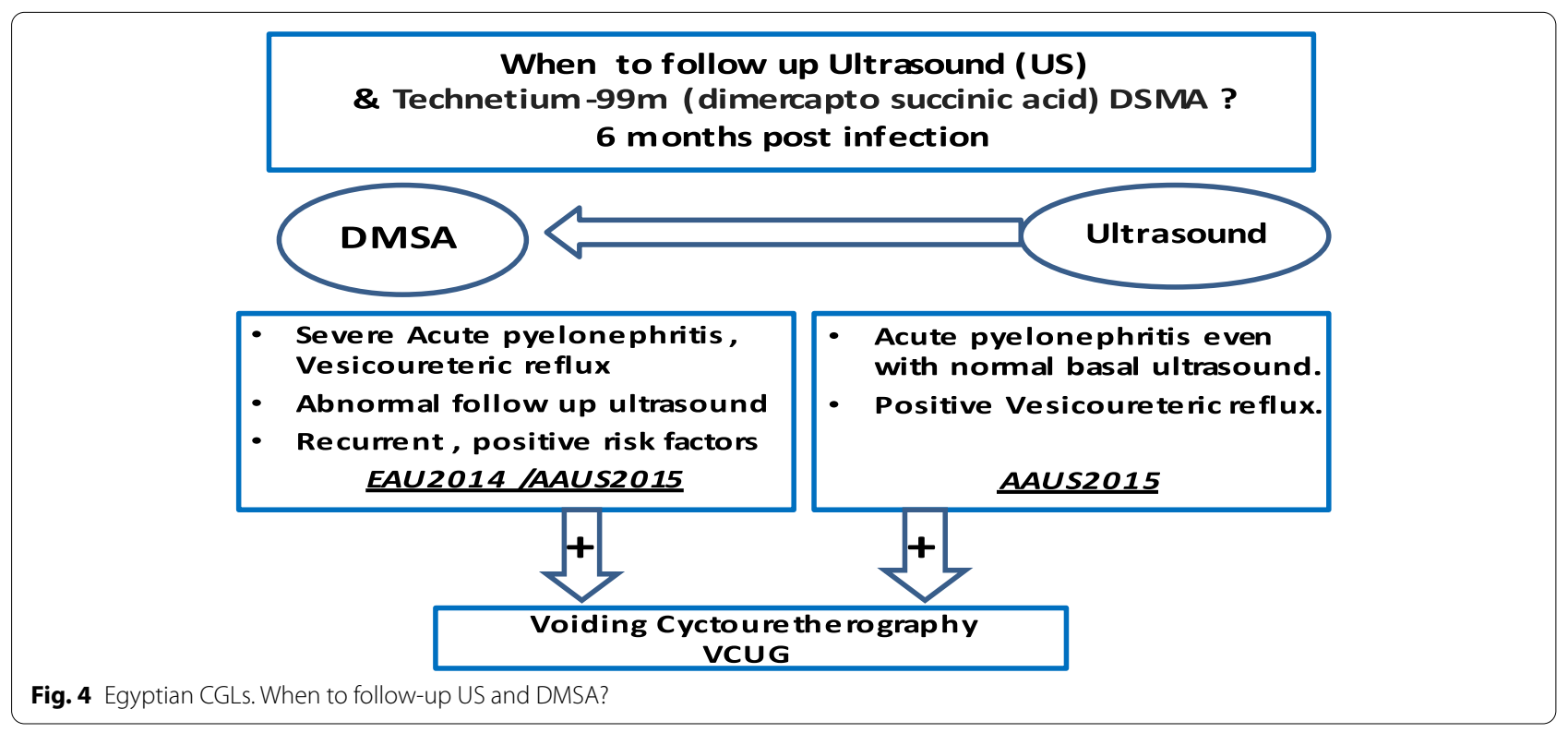




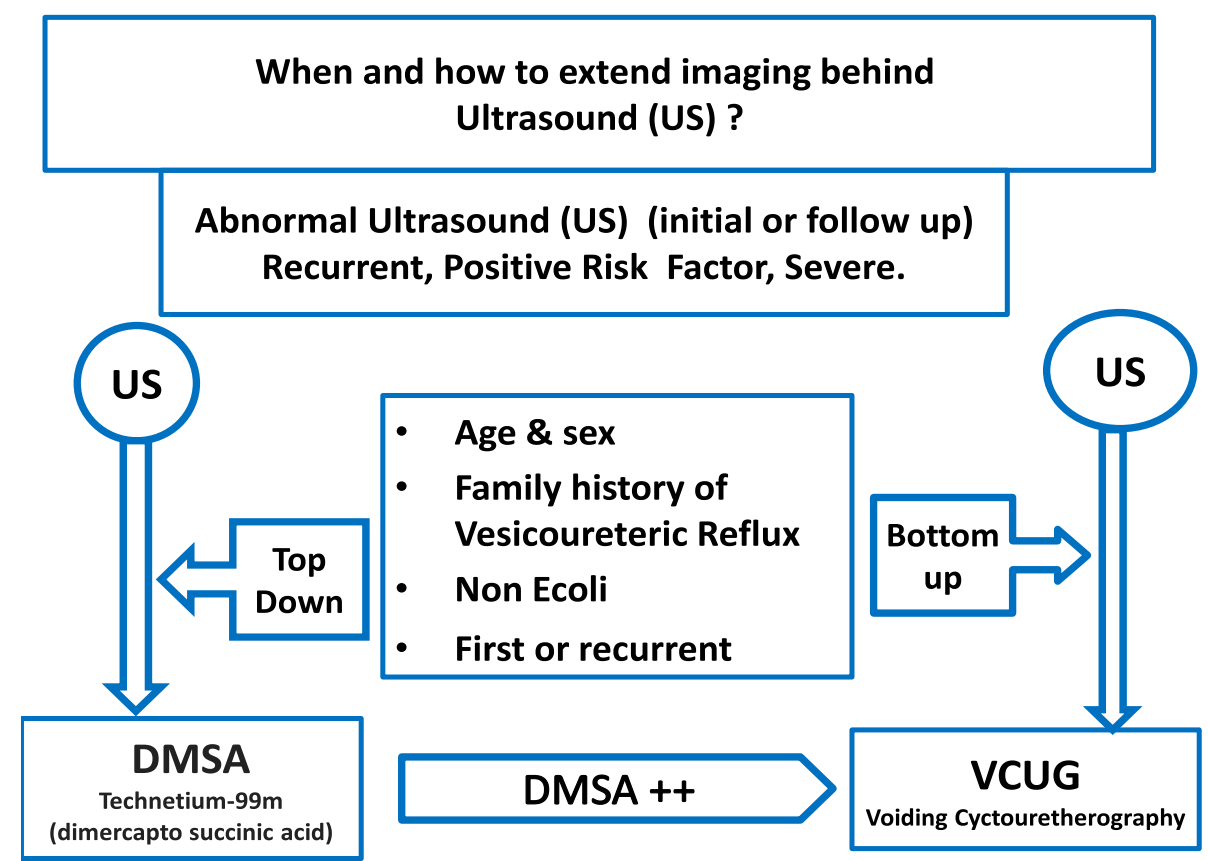

Fig. 5 When to extend imaging? Bottom-up or top-down approach? Factors to be considered in choosing the bottom-up or top-down approach include age, sex, first or recurrent, non-E. coli, and family history of vesico-ureteric reflux

positive family history of VUR, and abnormal RBUS. Extended imaging will avoid missing VUR and RS [30].

How to image (imaging plan)? Those with a critical presentation with suspected obstruction or male infant $<6$ months, infants of either sex, abnormal US (dilatation, hypodysplasia), need urological consultation for urgent interference (stent, diversion) and urgent imaging plan (MAC3 to diagnose obstruction, acute DMSA in renal hypodysplasia to detect scars, VCUG to diagnose PUV, VUR) as evident in our final imaging recommendation plan (Fig. 6).

DMSA is the gold standard for the diagnosis of acute pyelonephritis and renal scarring [31]. Acute DMSA during the acute phase of UTI is not recommended by most CGLs because of its high cost and radiation compared to its benefits [9]. It has selective indications, e.g. severe APN or congenital hypodysplasia (when reported by renal RBUS), or because of its diagnostic value in the acute phase that will suggest further imaging modality (L3, GR: C AAUS) [22, 28] (Fig. 6). Late DMSA is recommended 6 months after the acute phase to detect scars in those with severe APN, recurrent febrile UTI, highgrade VUR, abnormal renal US (basal or follow-up) (L3GRC AAUS 15) [22] [Fig. 4]. It could be done earlier than 6 months if recurrence occurs before the lapse of 6 months (LE3, GR: C) (AAUS) [22, 32, 33]. NICE 2016 recommends late DMSA (routine) for all atypical presentation (except > 3years of age) and recurrent at any age with febrile UTI with the exclusion of simple responsive first episode cases, to be only requested at recurrence [30].

VCUG is the gold standard imaging for the diagnosis and grading of VUR when compared to direct or indirect radionuclide scintigraphy or voiding ultrasonography $[10,18,22,30]$. It is recommended for diagnosis and grading of VUR. Either a top-down (US/DMSA/ \pm VCUG) or bottom-up approach (US/VCUG \pm DMSA) is used. The top-down approach is getting more commonly used in recurrent UTI, while in the first infection, VCUG is only indicated if either abnormal US or abnormal DMSA or both (LE2GR:B. AAUS) [22]. The bottomup approach is recommended after the abnormal US suggestive of VUR at initial assessment for febrile UTI to be followed with DMSA, only for those diagnosed to show VUR (LE2GR: B, AAUS) [22]. The benefit of using the top-down approach is to reduce the number of VCUG performance. Multiple factors, as age, VUR grade, and first or recurrent UTI, determine which approach to use $[9,22]$ (Figs. 4 and 5). EAU CGLs recommend at initial evaluation the bottom-up with US/VCUG and listed topdown as an option (LE2a) [34]. 


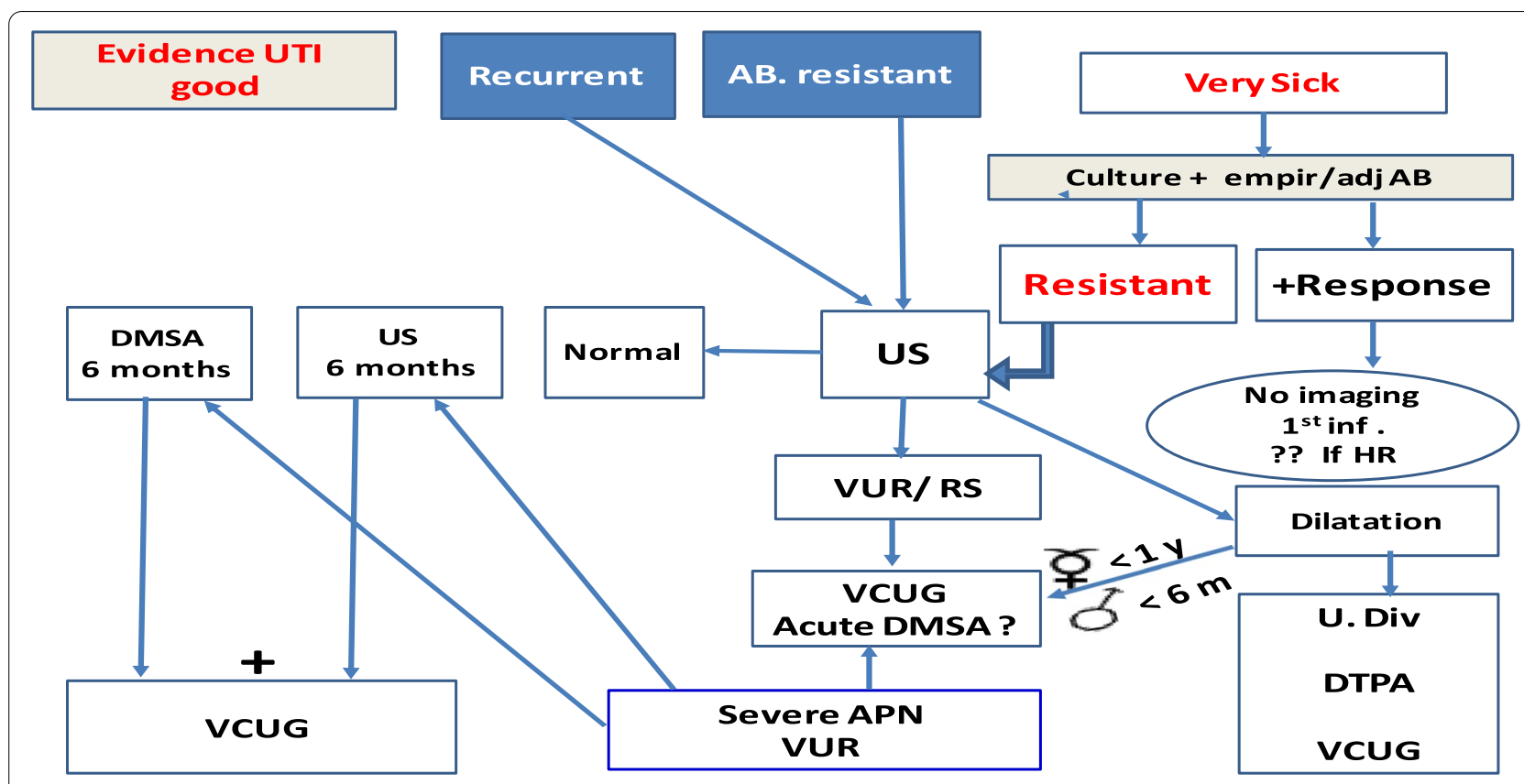

Fig. 6 National imaging recommendation plan. AB antibiotic, empir empirical, Adj AB adjusted antibiotic, US ultrasound, VUR vesico-ureteric reflux, RS renal scarring, VCUG voiding cystourethrography, APN acute pyelonephritis, DMSA Technetium-99m (dimercaptosuccinic acid), DMSA $6 \mathrm{~m} .6$ months post-infection, DTPA diethylenetriamine pentaacetic renogram, U. Div ureteric diversion

The national imaging plan was adapted from AAUS and EAU/ESPU guidelines to suit our community (Fig. 6). Extended imaging recommendations as mentioned are limited to certain indications and not routine. Reasons for including them in these CGLs in detailed algorithms or flow charts are related to our local UTI profile in Egypt that show a high prevalence of anomalies (CAKUT with UTI 76\% and with ESRD 33\%), VUR (18.3 to $22 \%$ with grade 4 representing $60-66 \%$ and grades 1-3 representing 34-44\%), and renal scarring 8-33\% (polar scars $4-8 \%$, total atrophy $11-18 \%$ ). Nineteen to $38 \%$ out of 200 kidneys with UTI showed impaired renal growth [4]. However, with advancements in evidencebased medicine, many of the traditional links between UTI, VUR, and renal scarring have been changed. Other high-risk factors showed significance. Also, anti-reflux surgery was limited to high-grade and unsterile VUR, with restriction of antibiotic prophylaxis to recurrent UTI and VUR. Overall, our national imaging CGLs already presented respect scientific recommendations mostly accepted by others but tailored to our own cultural status.

\section{Follow-up imaging and medical care recommendations}

1. Those with a simple, responsive, first attack with no previous abnormal imaging are advised to come back only on recurrence. Those with severe APN (with normal or abnormal US), or VUR, are advised to come back after 6 months for RBUS and DMSA. High-risk or recurrent UTI patients need repeated imaging in infancy and young age. All imaging reports should be documented and those with abnormal results should get patient/doctor appointment $[29,32]$.

2. Patients and their families should be oriented with details of treatment, local hygiene, and symptoms of recurrence; urine collection and storage for sampling; reasons for re-investigations (urine tests and/or imaging); and hazards of noncompliance. All patients' progress notes for UTI should be documented. Indicators of progress (blood pressure, kidney functions, proteinuria) are to be done every 6 months in bilateral and annually in unilateral lesions. Adolescent girls need monitoring at pregnancy. Transfer to adult service after the age of 16 years is crucial (consensus) [30].

\section{Conclusion}

Diagnosis and treatment show strong recommendations. Imaging plans depend on patient assessment. Referral to pediatric nephrologists and/or urologists is recommended in complicated cases. Follow-up after the age of 16 years in adult clinics is crucial. 


\section{Suggested areas for further research}

* Long-term cohort studies to establish links between UTI in infants and young children and reduced renal function and hypertension in adults

* New noninvasive procedures for urine collection away from contamination?

* Use of dynamic contrast RBUS for diagnosis of VUR

* Molecular genetics for primary familial VUR and asymptomatic bacteriuria

* Assessment of optimal treatment strategies (choice of $\mathrm{AB}$, oral vs IV, duration, $\mathrm{AB}$ prophylaxis)

* Imaging plans

\section{Abbreviations}

AAP: American Academy Pediatrics; AAUS: Asian Association Urinary tract infections Sexually transmitted disease; AB: Antibiotics; APN: Acute pyelonephritis; CAKUT: Congenital anomalies of the kidney and urinary tract; EAU: European Association Urology; EPCGC: Egyptian Pediatric Clinical Guidelines Committee; ESRD: End-stage renal disease; ESPU: European Society Pediatric Urology; HRF: High-risk factors; PIPOH: Patient Intervention Professionals Outcome Healthcare settings; PNWG: Pediatric Nephrology Work Group; UTI: Urinary tract infection; RBUS: Renal bladder ultrasound.

\section{Acknowledgements}

To Egyptian Pediatric Clinical Guidelines Committee EPCGC (Prof. Ashraf Abdel Baky Head of Committee) for boosting the idea, hosting the meetings, affording facilities, orientation, and training of the WG with EB skills needed for the task, communication with the international guidelines constitutions for getting consent as being reference sites, arrangement for local and international peer reviewing for validation of the statements after open discussion in conference meeting attended by great number of pediatricians to allow interactive discussion. Efforts of the committee to afford the implementation of CGLS in university-related hospitals, national hospitals, primary care service units, medical students, and post-graduate education and research programs deserve our utmost respect.

\section{Pediatric Nephrology Work Group}

Collaborating Bahia H Moustafa, Moftah M Rabie, Ihab Z El Hakim, Ahmed Badr, Moustafa El Balshy, Ragia Marei Ali

\section{External reviewers}

Pierre Cochat (Former S.G. of IPNA) Lyon University

Mohamad Eissa (Honorary board member of American Society Urology) Prof. Urology/Cairo University

Amr Sarhan Professor of Pediatric \& Pediatric Nephrology, Dean/Faculty of Medicine, Mansoura University

Neveen Soliman/Prof. Pediatrics \& Pediatric Nephrology, Vice Dean for Research \& Post-Graduate Affairs/Faculty of Medicine, Cairo University Sawsan Elmoselhy Prof. Pediatric \& Pediatric Nephrology/Ain Shams University Alaa Thabet Head Pediatric Nephrology Unit/Alexandria University

\section{Authors' contributions}

BHM: principal and corresponding author, author of introduction and imaging, and access to other parts. MMR and MGB: authors of treatment. IZEIH and RM: diagnosis and risk factors. AB: documentation and follow-up. NMK: selection of reference CGLS (AGREE 11), revise checklists for scoping. Egyptian Pediatric Clinical Guidelines Committee EPCGC (Prof. Ashraf Abdel Baky Head of Committee) approved the submitted version statements after local and international peer reviewing for validation. Pediatric Nephrology Work Group: Bahia H Moustafa ${ }^{1,2 *}$, Moftah M Rabie ${ }^{3}$, Ihab Z El Hakim ${ }^{4}$, Ahmed Badr ${ }^{1,5}$, Moustafa El Balshy ${ }^{6}$, Ragia Marei Ali ${ }^{4}$. We all as contributors participated in the content, analysis, and interpretation of the data as mentioned. All authors have read and approved the manuscript. We also agreed that Professor Bahia Moustafa who writes the first draft of the manuscript to be the corresponding author. As stated in the cover letter, there were no funding, no conflict of interests, and no previous publication or permissions. We accept copy transfer to the journal if accepted. We give rights to the corresponding author to make necessary changes requested by the journal on our behalf.

\section{Authors' information}

Professor Bahia Hassan Moustafa is a Professor and Consultant of Pediatric Nephrology, President of African Pediatric Nephrology Association (AFPNA) (2000-2006), Counselor of International Pediatric Nephrology Association (IPNA) (2000-2006), Head of Pediatric Nephrology and Dialysis Unit, Cairo University Children Hospitals 2005-2009, and Head of Pediatrics Unit, Cairo University 2008-2009. Founder of Kidney transplantation program in Cairo University Children Hospital 2009.

\section{Funding}

The authors declare that this research work did not receive any fund.

Availability of data and materials

Not applicable.

\section{Declarations}

\section{Ethics approval and consent to participate}

Not applicable, being guidelines.

\section{Consent for publication}

Not applicable, being guidelines.

\section{Competing interests}

The authors declare that they have no competing interests.

\section{Author details}

${ }^{1}$ Department of Pediatrics, Pediatric Nephrology \& Transplantation Unit, Kasr Al Ainy Faculty of Medicine, Cairo University, 35 Elsheikh Aly Youssef Kasr Alainy, Cairo 11441, Egypt. ${ }^{2}$ Department of Pediatrics, Pediatric Nephrology Unit, Faculty of Medicine, Al Azhar University, Cairo, Egypt. ${ }^{3}$ Department of Pediatrics, Pediatric Nephrology Unit, Faculty of Medicine, Ain Shams University, Cairo, Egypt. ${ }^{4}$ Department of Pediatrics, Armed Forces Medical College, Cairo, Egypt. ${ }^{5}$ Department of Pediatrics, Pediatric Nephrology Unit, Faculty of Medicine, Banha University, Banha, Egypt. ${ }^{6}$ Department of Community, Kasr Al Ainy Faculty of Medicine, Cairo University, Cairo, Egypt.

Received: 4 October 2020 Accepted: 19 March 2021

Published online: 09 December 2021

\section{References}

1. Mohammed A, Abdelfattah M, Ibraheem A, Younes A (2016) A study of asymptomatic bacteriuria in Egyptian school-going children. Afr Health Sci 16(1):69-74

2. Moustafa B (2010) Ten years focus on urinary tract infections among Egyptian children: review of four studies on children with UTI followed in Cairo University Children Hospital through years 89 to 2000. 10th. Egyptian Society Pediatric Nephrology and Transplantation (ESPNT) conference, Cairo

3. El-Gamal SA, Saleh LH (1991) Asymptomatic bacteriuria in school children in a rural area, Egypt. J Egypt Public Health Assoc 66(1-2):113-121

4. Moustafa B (2018) Kidney transplantation registry 2009/2017 Cairo University Children Hospital. IPNA/IKD Educational Workshop, Cairo

5. Moustafa B (2003) Pediatric nephrology in Africa. Pediatr Nephrol 75:1498-1504 5th ed. Lippincott Williams \& Wilkins 
6. Ammenti A, Cataldi L, Chimenz R et al (2012) Italian Society of Pediatric Nephrology. Febrile UTI in young children: recommendation for the diagnosis, treatment and follow up. Acta Pediatr 101(95):451-445

7. Appraisal of Guidelines for Research and Evaluation (AGREE II) Instrument (2017) Available from https://www.agreetrust.org/wp- content/uploads/ 2017/12/AGREE-II-Users-Manual-and-23-item-Instrument-2009-update2017.pdf. Accessed Jun 2019

8. Yang SS, Han CH, Tsai JD, Kanematsu A (2015) UAA/AAUS (Urological Association of Asia/Asia Association of UTI \& STI): asian guidelines for UTI \& STId Section of "asian guidelines for UTI in children".

9. Stein R, Dogan HS, Hoebeke P, Kočvara R, Nijman RJ, Radmayr C, Tekgül S (2015) Urinary tract infections in children: EAU/ESPU guidelines. Eur Urol 67(3):546-558

10. Roberts KB (2011) Urinary tract infection: clinical practice guideline for the diagnosis and management of the initial UTI in febrile infants and children 2 to 24 months. Pediatrics. 128(3):595-610

11. Amer YS, Elzalabany MM, Omar TI, Ibrahim AG, Dowidar NL (2015) The 'Adapted ADAPTE': an approach to improve utilization of the ADAPTE guideline adaptation resource toolkit in the Alexandria Center for evidence-based clinical practice guidelines. J Eval Clin Pract 21(6):1095-1106

12. Clinical practice guideline for urinary tract infections in children Argon Institute of Health Science (1+CS), 2011. Grupode trabajo sobre GPC. Elaborcion de practica clinica en el Sestema Nacional de Salud. Manual metedologico .Madrid: Plan Nacional para el SNS del MSC. Instituto Argones de la Salud -1+CS; 2007. Guias de practica clinica en el SNS:1+CS,N 2006/1

13. Tsai J, Yang S (2016) Diagnosis of pediatric urinary tract infections. Urol Sci 27(3):131-134

14. Foxman B (2002) Epidemiology of urinary tract infections: incidence, morbidity, and economic costs. Am J Med 113(1)

15. Ma JF, Shortliffe LM (2004) Urinary tract infection in children: etiology and epidemiology. Urol Clin N Am 31:517-526 ix-X

16. Shaikh N, Morone NE, Bost JE, Farrell MH (2008) Prevalence of urinary tract infection in childhood: a meta-analysis. Pediatr Infect Dis J 27:302-308

17. Levy I, Comarsca J, Davidovits M, Klinger G, Sirota L, Linder N (2009) Urinary tract infection in preterm infants: the protective role of breastfeeding. Pediatr Nephrol 24(3):527-531

18. Finnell SM, Carroll AE, Downs SM (2011) Subcommittee on urinary tract infection. Technical report-diagnosis and management of an initial UTI in febrile infants and young children. Pediatrics. 128(3):e749-e770

19. Kaufman J, Fitzpatrick P, Tosif S, Hopper SM, Donath SM, Bryant PA, Babl FE (2017) Faster clean catch urine collection (Quick-Wee method) from infants: randomised controlled trial. BMJ 357:j1341

20. Hoberman A, Wald ER, Reynolds EA, Penchansky L, Charron M (1994) Pyuria and bacteriuria in urine specimens obtained by catheter from young children with fever. J Pediatr 124(4):513-519

21. Ottolini MC, Shaer CM, Rushton HG, Majd M, Gonzales EC, Patel KM (1995) Relationship of asymptomatic bacteriuria and renal scarring in children with neuropathic bladders who are practicing clean intermittent catheterization. J Pediatr 127:368-372

22. Tsai JD (2015) Imaging studies after urinary tract infections in children. AAUS, Asian Guidelines for UTI \& STId Section of "Asian Guidelines for UTI in Children"

23. Ladhani S, Gransden W (2003) Increasing antibiotic resistance among urinary tract isolates. Arch Dis Child 88(5):444-445

24. Brady PW, Conway PH, Goudie A (2010) Length of intravenous antibiotic therapy and treatment failure in infants with urinary tract infections. Pediatrics. 126(2):196-203

25. Marquiz I, Plazzi DL (2016) Antibiotic treatment for UTI. The clock is ticking. JAMA Pediatr 170(90):834-835

26. Shaikh N, Mattoo TK, Keren R, Ivanova A, Cui G, Moxey-Mims M, Majd M, Ziessman HA, Hoberman A (2016) Early antibiotic treatment for pediatric febrile urinary tract infection and renal scarring. JAMA Pediatr 170(9):848-854

27. Williams G, Craig JC (2011) Long term antibiotics for preventing UTIs in children. Cochrane Database Syst Rev 2011(3):CD001534. https://doi.org/ 10.1002/14651858.CD001534.pub3

28. Robinson JL, Finlay JC, Lang ME, Bortolussi R, Canadian Pediatric Society, Community Pediatrics Committee (2014) Urinary tract infections in infants and young children. Pediatr Child Health 19(6):315-319
29. Soliman NA, Ali Rl, Ghobrial EE, Habib El, Ziada AM (2015) Pattern of clinical presentation of congenital anomalies of the kidney and urinary tract among infants and children. Nephrology. 20(6):413-418

30. Price E, Pallett A, Gilbert RD, Williams C (2010) Microbiological aspects of the UK National Institute for Health and Clinical Excellence (NICE) guidance on urinary tract infection in children. J Antimicrob Chemother 65(5):836-841

31. Ricabona M, Avni FE, Blickman JG, Dacher J-N, Doirge K, Lobo Ml et al (2008) Imaging recommendations in pediatric uroradiology. Minutes of the BSPR work group. Session on UTI, fetal hydronephrosis, UT ultrasonography and voiding cysto urethrography, Barcelona, Spain, JUNE 2007. Pediatr Radiol 39:138-145

32. Marks SD, Gordon I, Tullus K (2008) Imaging in childhood urinary tract infections: time to reduce investigations. Pediatr Nephrol 23(1):9-17

33. Hoberman A, Charron M, Hickey RW, Baskin M, Kearney DH, Wald ER (2003) Imaging studies after a first febrile urinary tract infection in young children. N Engl J Med 48(3):195-202

34. Tekgül S, Riedmiller H, Hoebeke P, Kočvara R, Nijman RJ, Radmayr C, Stein R, Dogan HS (2012) EAU guidelines on vesicoureteral reflux in children. Eur Urol 62(3):534-542

\section{Publisher's Note}

Springer Nature remains neutral with regard to jurisdictional claims in published maps and institutional affiliations.

\section{Submit your manuscript to a SpringerOpen ${ }^{\circ}$ journal and benefit from:}

- Convenient online submission

- Rigorous peer review

- Open access: articles freely available online

- High visibility within the field

- Retaining the copyright to your article

Submit your next manuscript at springeropen.com 